\title{
Informing the development of science exhibitions through
} educational research

\section{Laherto, Antti}

2013-06

Laherto , A 2013 , ' Informing the development of science exhibitions through educational research ' , International Journal of Science Education, Part B: Communication and Public Engagement, vol. 3 , no. 2 , pp. 121-143 . https://doi.org/10.1080/21548455.2012.694490

http://hdl.handle.net/10138/308777

https://doi.org/10.1080/21548455.2012.694490

acceptedVersion

Downloaded from Helda, University of Helsinki institutional repository.

This is an electronic reprint of the original article.

This reprint may differ from the original in pagination and typographic detail.

Please cite the original version. 
This is an Accepted Manuscript of an article published by Taylor \& Francis in International Journal of Science Education, Part B: Communication and Public Engagement on June, 2013, available online: https://doi.org/10.1080/21548455.2012.694490:

Laherto, A. (2013). Informing the Development of Science Exhibitions Through

Educational Research. International Journal of Science Education, Part B, 3(2), 121143, DOI: $10.1080 / 21548455.2012 .694490$

\title{
Informing the development of science exhibitions through educational research
}

\begin{abstract}
This paper calls for greater use of educational research in the development of science exhibitions. During the past few decades, museums and science centres throughout the world have placed increasing emphasis on their educational function. Although exhibitions are the primary means of promoting visitors' learning, educational research is not often utilised when designing these learning environments. Rather, the development of exhibitions in museums and science centres tends to rely on the know-how of the staff. Reviewing and engaging in science education research would complement this expertise and support the educational role of science exhibitions. This theoretical paper therefore suggests such a research-based approach by adapting the Model of Educational Reconstruction for the purpose of exhibition development following the idea of the Model for the Personal Awareness of Science and Technology. The former model serves as a general framework to involve analytical and empirical research in the development of learning environments, while the latter model provides a specific view of visitors' learning in interaction with exhibits. The study shows how these constructivist models can be interconnected in order to apply educational research in improving the long-term learning profit of exhibition visits. The idea is illustrated with an example concerning the research-based development of a nanoscience exhibition.
\end{abstract}

Keywords: educational reconstruction, exhibit design, informal education, learning environment, personal awareness of science and technology 


\section{Introduction}

\section{The problem}

The educational value of informal learning environments has been increasingly recognized during the past decades. As learning is regarded as a learner-led and lifelong process, settings such as museums and science centres1 play an important role in complementing formal education and in contributing to scientific and technological literacy (Bybee, 2001; Falk, Storksdieck, \& Dierking, 2007; Mehta, 1997). Indeed, museums have undergone a major shift in terms of their role and justification in society (for a closer examination of this development, see Hooper-Greenhill, 1992, and B. Lord, 2001). They are now primarily considered as educational2 institutions.

Exhibitions are the main mode of communication in museums and science centres, and thereby also the main means for executing the educational function of these institutions (Allen, 2004; Hooper-Greenhill, 1994; B. Lord, 2001). Thus, the process of developing exhibitions should be thoroughly informed by educational knowledge, concerns and expertise. This poses additional requirements for the museum staff and other designers, who must also consider many other aspects and constraints, including practical factors associated with the institution in which the exhibition will take place, sponsors' interests, commercial perspectives, the usability and durability of the exhibits, and the resources for the project (see e.g. Davidsson \& Sørensen, 2010; G. Lord, 2001; Schauble \& Bartlett, 1997). Given this multitude of competing claims and interests, many museums and science centres also try to ensure that educational viewpoints are considered by upholding educational departments and including pedagogues or educators in exhibition development.

The educational potential of museums can be further improved by utilising research findings during the process of exhibition development. Many scholars have argued for the importance of making exhibition development more research-based (e.g. Allen, 2004; Falk \& Dierking, 2000; Grewcock, 2001; G. Lord, 2001; Schauble \& Bartlett, 1997). Such a need has frequently been highlighted by museum professionals, for example in the context of the wideranging project 'In Principle, In Practice: A Learning Innovation Initiative on Museum Learning' (see Falk, Dierking, \& Foutz, 2007). Most museums, indeed, take advantage of research findings to some extent, for example by carrying out their own visitor studies in order to lay some groundwork for future exhibitions. In making an exhibition, knowledge of the audience is nowadays considered equally important to the knowledge of the objects to be presented (Hooper-Greenhill, 1992, pp. 208-211). It is also understood that visitors want to be actively involved - both physically and mentally - during their visit (e.g. Falk \& Storksdieck, 2010). Museums are therefore developing new practices for incorporating visitors' perspectives - such as their beliefs, attitudes, values and habits - into exhibition development. However, Hooper-Greenhill (1994) has argued that despite the changes in museum ideology and aims, and all the recommendations for in-depth front-end evaluation of

1 In this paper the term 'museum' mostly refers to science museums, and specifically to hands-on science museums and science centres.

2 This educational function should not, however, be seen as similar to the role of formal education, nor as a counterpoint to the museums' aim of entertaining the visitors (see e.g. Hooper-Greenhill, 1994; B. Lord, 2001). Further discussion on this will follow in the paper. 
visitors' perspectives, very few museums in fact carry out efficient visitor needs assessments. Even if they do, connecting these findings to practice remains problematic (see Falk, Dierking, \& Foutz, 2007).

Furthermore, reviewing studies that have been carried out outside the museum in question would deepen the visitor-oriented approach and understanding of educational issues. Potentially useful research domains for exhibition development not only include the fields of informal learning and museum education. While these fields have been growing rapidly during the past decades, the vast majority of educational research still focuses, quite naturally, on learning and teaching within the formal educational system. By reviewing such literature on empirical as well as analytical research, exhibition developers can gain valuable insights to be utilized in the process while still keeping in mind the essential differences between formal and informal educational settings, and the characteristics of an exhibition as a learning environment. When developing science exhibitions, research on science education is naturally the main field of educational research to draw on. Reinders Duit (2007) distinguishes the domains of science education research as follows: (1) analysis of content structure; (2) research on teaching and learning2; (3) development and evaluation of instruction / instructional design; and (4) research on curricular issues and science education policies. Given the educational role of museums, these domains can offer a wider scope of useful findings for exhibition developers than the field of museum research alone.

This paper discusses how findings from all the domains of science education research (Duit, 2007), together with findings from museum research, can be used when laying the groundwork for an exhibition. Here, it is proposed that utilizing such research supports the educational function of these environments by providing at least some answers to the questions that, according to Barry Lord (2001, p. 19), must be answered in the early phase of exhibition development: 'What meanings do we wish to communicate?', 'To whom do we intend to communicate these meanings?' and 'What are the most appropriate means of communicating these meanings?'

\section{Formalizing the process of exhibition development}

Even if the team developing an exhibition is aware of, and has access to the findings of educational research (e.g. with the support of the museum's educational department), it may be difficult in practice to find the time and convenient means for the effective use of such knowledge. In the complex and demanding process of exhibition development, such issues easily give way to more practical and acute challenges the staff have to deal with. There are usually no formal procedures or guidelines for exhibition development that would ensure that all aspects are considered in a systematic and consistent way. Rather, the process mainly relies on the practical and tacit professional knowledge and experience of museum staff and other designers, as well as their ability to take the various aims and concerns into account during the process and to make the 'best fit' (Grewcock, 2001) out of them (cf. Mortensen, 2010b; Schauble \& Bartlett, 1997).

2 The second domain includes, very importantly, studies on learners' interests, conceptions and affective positions. 
In the literature, the need to complement the expertise of the staff and systematise the process of exhibition development has been pointed out by many scholars (e.g. Allen, 2004; G. Lord, 2001; Schauble \& Bartlett, 1997). Most museum research has only indirect implications for exhibit design (cf. Mortensen, 2010b). Literature on museum learning includes a multitude of studies that examine how the characteristics of an exhibit influence visitors' interactions, but does not, however, provide a prescriptive model for how to exactly use that knowledge in exhibition development. Accordingly, some suggestions for formalising the process have been presented (G. Lord, 2001; Mortensen, 2010b; Schauble \& Bartlett, 1997). Recently, exhibition development (including the sub-processes of epistemological and museumpedagogical development) has been discussed by using a model of Museographic transposition (Gouvêa de Sousa et al., 2002; Mortensen, 2010b; Simonneaux \& Jacobi, 1997). The model describes how scientific knowledge is reduced and adapted, and then supplemented and reconstructed when designing and implementing exhibits. However, the model does not specify how all the above-mentioned domains of educational research could be applied in the process of exhibition development. While the model recognises that the museographic form essentially influences the outcome of the transposition, i.e. the exhibition milieu (Mortensen, 2010b), it does not suggest how these exhibition characteristics should be addressed in a research-based way.

The aim of this paper is to complement these formalisations by suggesting how the process of exhibition development may be informed by educational research. In searching for a model for this purpose, it is useful to turn to the literature on formal education in schools3. There, special attention has been paid to the seamless integration of educational research and development of practical educational solutions (e.g. teaching-learning sequences, courses, and instructional materials). This has been the main agenda of the design-oriented research tradition that has been increasingly popular both in Europe and the USA (see e.g. Edelson, 2002). The models within this tradition - such as developmental research (Lijnse, 1995), design experiments (Brown, 1992; Cobb, Confrey, diSessa, Lehrer, \& Schauble, 2003) and other variants of Design-Based Research (Tiberghien, Vince, \& Gaidioz, 2009) - have a dual nature: they seek to contribute to educational theory and simultaneously lead directly to useful products or practices. This paper draws on one of these design-oriented research approaches, the Model of Educational Reconstruction (Duit, Komorek, \& Wilbers, 1997; Duit, Gropengiesser, \& Kattman, 2005; Duit, 2007). Although originally created for classroom purposes, the model is very general and flexible, and can be adjusted to take into account the characteristics of informal settings such as science centre exhibitions. These characteristics are 'inserted' into the model by employing the Model for the Personal Awareness of Science and Technology (Stocklmayer \& Gilbert, 2002), involving a view of the nature of learning in an exhibition that also has implications for exhibit design.

The suggestions in this paper mostly concern the first phase of the exhibition planning process, i.e. the development phase (G. Lord, 2001, p. 4). The next steps of the exhibition project, the phases of design and implementation, are chiefly beyond the scope of this paper. This is why, for instance, the aspects of exhibit design and usability - which are crucial in terms of a visitor's experience during the visit - are not addressed in the following. The paper focuses on how educational research may be applied when laying the groundwork for an

3 Similarly, the idea of museographic transposition also originates in French school didactics, namely the concept of didactic transposition (see Mortensen, 2010b). 
exhibition. The paper does not suggest a complete model for exhibition engineering, which is a far more complicated process including a variety of important considerations beyond the educational research findings.

In fact, the use of educational research alone includes too many choices to be prescriptively modelled in detail. The present paper cannot give a recipe. Instead, it attempts to catalyse discussion on the potential of educational research in exhibition development, and to give an overview of the resources available. Choices in using these resources necessarily remain at the professional discretion of the museum personnel. Moreover, preferred parts of the suggested model can be used separately, considering the characteristics of the actual exhibition project.

The following section introduces the Model of Educational Reconstruction and adjusts it for the purpose of exhibition development. After that, a generic procedure for using educational research in exhibition development is suggested. The suggestion is illustrated by discussing an example concerning the research-based development of an exhibition on nanoscience. The paper concludes with discussion on the outlined approach.

\section{The Model of Educational Reconstruction in exhibition development}

\section{The Model of Educational Reconstruction (MER)}

The Model of Educational Reconstruction (Duit et al., 2005) is a methodological framework that combines analytical and empirical educational research with the development of practical educational solutions. The model was developed in the mid-1990s by Reinders Duit, Harald Gropengiesser, Ulrich Kattman and Michael Komorek, and is based on a continental European view of science education and the German educational tradition (Duit et al., 1997). One of the fundamental ideas of the model is that the content structure for instruction cannot be taken directly from the science content structure, but has to be specially (re)constructed by paying attention to the educational goals as well as students' cognitive and affective perspectives (Duit et al., 1997; Duit, 2007; Komorek \& Duit, 2004).

MER has a moderate constructivist orientation in two aspects. Firstly, learning is seen as an active construction process based on an individual's pre-existing knowledge. Therefore, the development of learning environments requires an awareness of learners' prior conceptions. Secondly, scientific knowledge is considered as a human construction. According to this epistemological position, a field of science does not have any 'true' content structure for instruction; all the presentations of the content are subjective reconstructions based on certain aims. Thus, the content structure for science education must also be reconstructed from educational aims and concerns rather than derived solely from science issues (Duit et al., 1997; Duit, 2007; Komorek \& Duit, 2004; van Dijk \& Kattmann, 2007).

According to the model, when developing educational solutions, the science content matter and student's conceptions must be equally taken into account and carefully linked together (Duit, 2007; van Dijk \& Kattmann, 2007). The model's three components and their close 
interplay are depicted in Figure 1. It is essential in MER that knowledge gained in one of the components influences the progress and conclusions in the two other components.

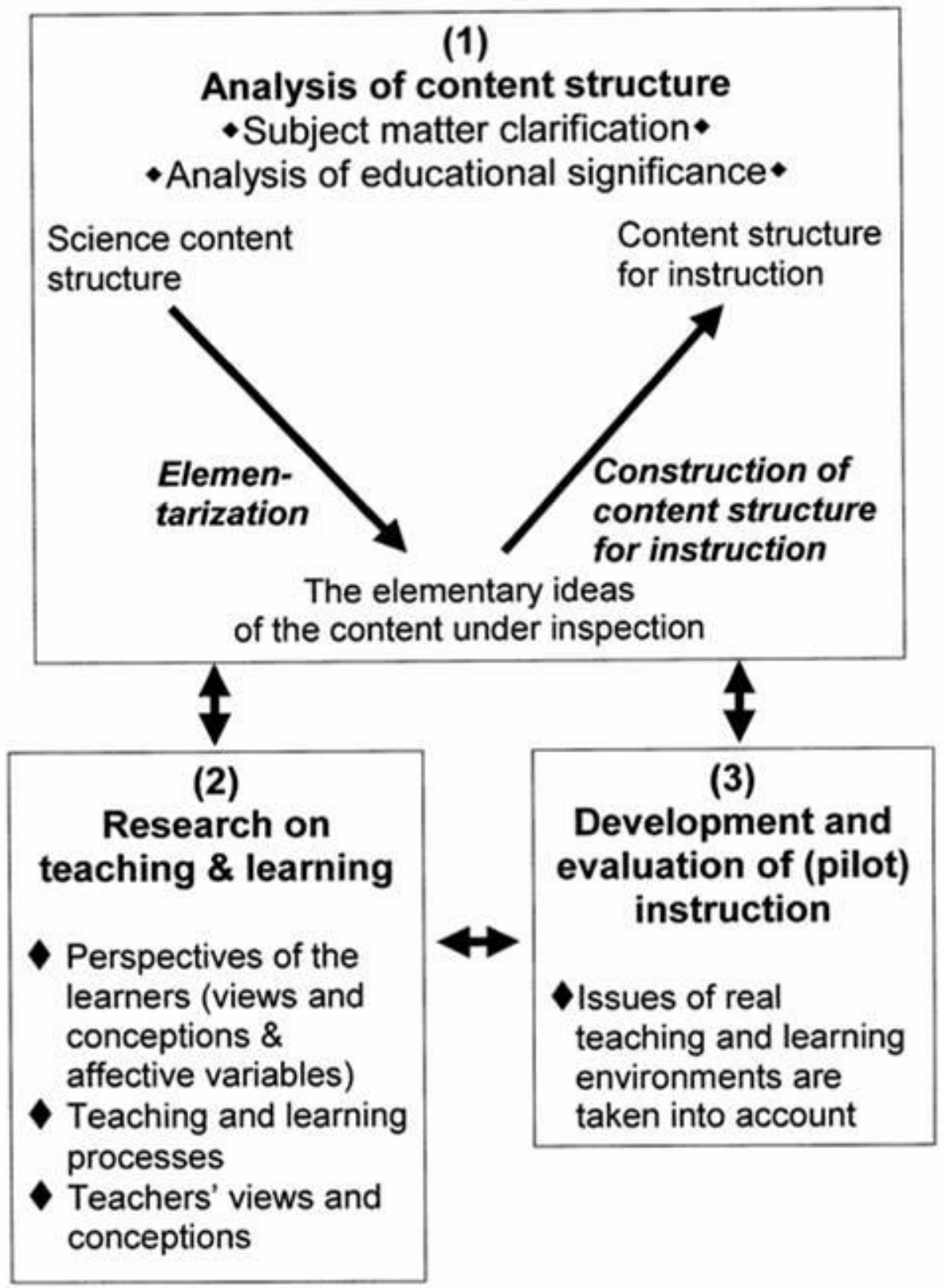

Figure 1. The model of educational reconstruction (Duit, 2007, p. 6).

Previously, MER has been employed in developing teaching-learning sequences on several physical topics, including chaos theory (Duit et al., 1997) and non-linear systems (Komorek $\&$ Duit, 2004). The model has also been used in teaching at the university level, where educational reconstructions have been carried out to create a physics laboratory course for university students (Neumann, Schumacher, \& Welzel, 2005) and to improve physics teacher 
education (Aiello-Nicosia \& Sperandeo-Mineo, 2000). More recently, MER has been applied in developing a further model for science teacher education (van Dijk \& Kattmann, 2007).

These previous applications of MER have dealt with formal educational settings. The present paper explores the potential of the model in the development of informal learning environments.

\section{Applicability of MER for exhibition development}

MER is a very general methodological framework, and thereby flexible enough to be applied to the development of any learning environment - including informal settings. The basic structure of the model (Fig. 1) appears to be well suited to research-based exhibition engineering, because the close interplay of the three components serves the general purposes of studying and developing settings such as exhibitions. However, an important emphasis must be added to the model when applying it to informal environments. Namely, as Duit (2007, p. 9) points out, MER does not explicitly take into account the broader context of the learning environment under development. The general goals of science education are certainly considered during the process, but since the model primarily deals with science instruction at school, the construction and revision of these wider goals is not the focus. The model considers the general goals of science education to be 'given' by the curriculum; they do not have to be thoroughly analysed in the process. The model consequently lacks the fourth domain of science education research as classified by Duit (2007), 'Research on curricular issues and science education policies'.

The situation is, however, somewhat different when developing an informal learning environment with no constraints and goals imposed by the curriculum. Thus, in this paper the model is enriched by adding specific emphasis on the formation of educational goals for an exhibition. This aspect deals with the domain of science education that is missing from MER, i.e. the one that "concerns features of the educational system in which science instruction is embedded' (Duit, 2007, p. 9). These features need thorough consideration, since the educational aims and the nature of learning in museums differ greatly from those of schools (further discussion on this follows). The aims must, above all, be broad enough to encompass the personal interests and conceptions of the visitors.

MER must be specified with a view of learning in a science centre, i.e. an interpretation of visitors' interactions with the exhibits and the aims of the visit, in order to be used in exhibition engineering. The approach suggested in this paper uses the model for the Personal Awareness of Science and Technology (Stocklmayer \& Gilbert, 2002) to deliver such a view and to render the general framework of MER specific enough to be helpful in developing exhibitions.

Representing the nature of learning in an exhibition: the Model for the Personal Awareness of Science and Technology (PAST) 
Learning in informal contexts has been defined, for example, as 'learning that is selfmotivated, voluntary, guided by learner's needs and interests, learning that is engaged in throughout his or her life' (Dierking, Falk, Rennie, Anderson, \& Ellenbogen, 2003). The model for PAST, proposed by Susan Stocklmayer and John Gilbert (2002), addresses the characteristics of exhibitions as learning environments, as well as modern learning theory, better than the much-criticized idea of 'public understanding of science', which resembles the idea of the 'deficit model' (Wynne, 1993). The model for PAST has a personal constructivist perspective that is in line with the contemporary view of museum learning, in which the audience is no longer seen as a passive and undifferentiated 'general public' (cf. HooperGreenhill, 1992; Rennie \& Johnston, 2004).

According to the model, each individual has his or her own personal awareness of science and technology, i.e. 'a set of attitudes, a predisposition towards science and technology, which is based on beliefs and feelings and which is manifest in a series of skills and intentions' (Gilbert \& Stocklmayer, 2001, p. 43). A science centre visit can induce experiences that interact with visitors' PAST (see Fig. 2). These experiences are framed by any ideas, objects, events or processes that are retrieved from visitor's memory when (s)he uses an exhibit; Stocklmayer and Gilbert (2002) emphasise that these remindings form the basis for interpreting the exhibit. A fruitful experience triggers memories that are related to the scientific and technological ideas presented in the exhibition, and/or creates new memories that can later be used in understanding these ideas (Afonso \& Gilbert, 2006). Through these subsequent, related experiences, the visitors' PAST evolves bit by bit, at some time leading to an understanding of some scientific and technological ideas, products and their implications, i.e. the target of the exhibits (Fig. 2). 


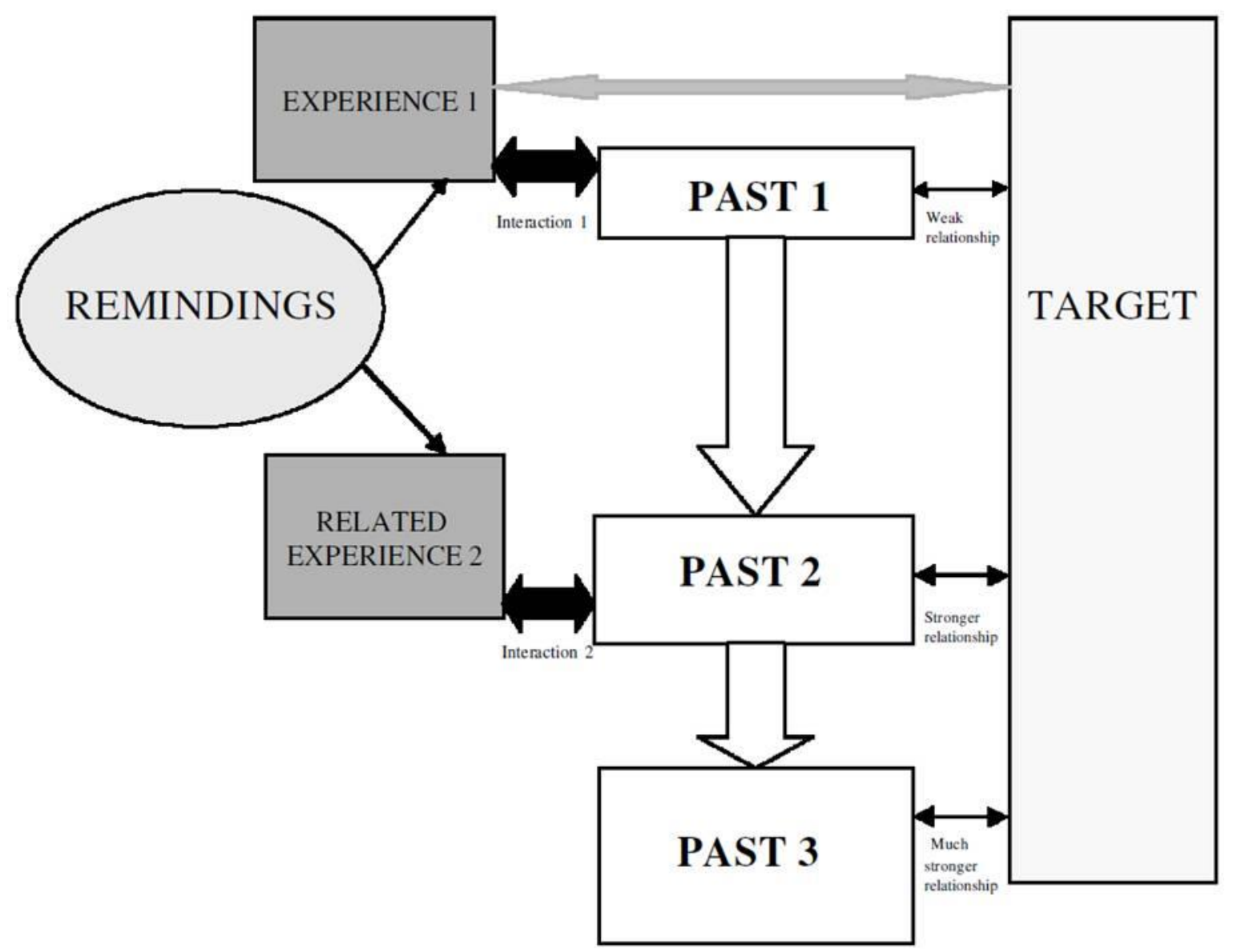

Figure 2. The model for the PAST (Stocklmayer \& Gilbert, 2002, p. 854).

The model for PAST thereby emphasises that the educational significance of an exhibition visit arises in the long term, and should not be considered in terms of immediate cognitive and affective outcomes (Stocklmayer \& Gilbert, 2002). The view is shared by many scholars in the field of museum learning who have paid increasing attention to the long-term impacts of visits (see e.g. Anderson, Storksdieck, \& Spock, 2007; Rennie \& Johnston, 2004). This is connected to a wider change in how the impact of museums is seen. Miles and Tout (1991) argued that the sense of disappointment when looking at the typically poor learning outcomes during an exhibition visit stems from a misconception of what museums are. They are 'places people visit for a variety of social reasons, places which offer, amongst other things, opportunities for learning if, and only if, visitors decide that this is what they want' (Miles \& Tout, 1991, pp. 549). Each visitor's learning experience is nowadays perceived as highly complex and personal (see e.g. Falk \& Storksdieck, 2010; Rennie \& Johnston, 2004). The model for PAST embodies the idea of totally unrestricted visitor choice in what to attend and what to learn - a feature that differs greatly from formal education and which Allen (2004) proposes as 'the single greatest constraint underlying exhibit design'.

Through this view of learning, the model for PAST also combines the dual role of museums and science centres in entertaining and in educating the audience (Gilbert \& Stocklmayer, 2001). These aims are sometimes seen as competing (cf. Allen, 2004), but most scholars 
argue that this conception is mainly due to the school-based interpretation of 'education' instead of seeing museum learning as personal, participative, exploratory, activity-based and informal (Hooper-Greenhill, 1994; B. Lord, 2001).

As the model for PAST is employed in exhibition development, the challenge of exhibit design becomes a challenge of creating appropriate experiences, related to some aspect of the target, that are likely to arouse remindings in visitors and interact fruitfully with their PAST. When carrying out research-based exhibition development, each of these elements of the model should be considered in the light of research findings. In the following, it is suggested how the development process can be informed by the content-centred and the visitor-centred studies carried out, or reviewed, within the Model of Educational Reconstruction.

\section{The use of educational research during the process of science exhibition development}

While the three components of MER are closely intertwined (see Fig. 1), applying the model in practice requires that the process is divided into a sequence of steps, i.e. certain concrete activities of research and development. The procedure for employing educational research in the different phases of exhibition development is outlined in Figure 3 and discussed in the following. The procedure is developed on the foundation of the basic Model of Educational Reconstruction (Fig. 1) and to some extent resembles the practical applications of it reported by Duit, Komorek and Wilbers (1997) and Komorek and Duit (2004).

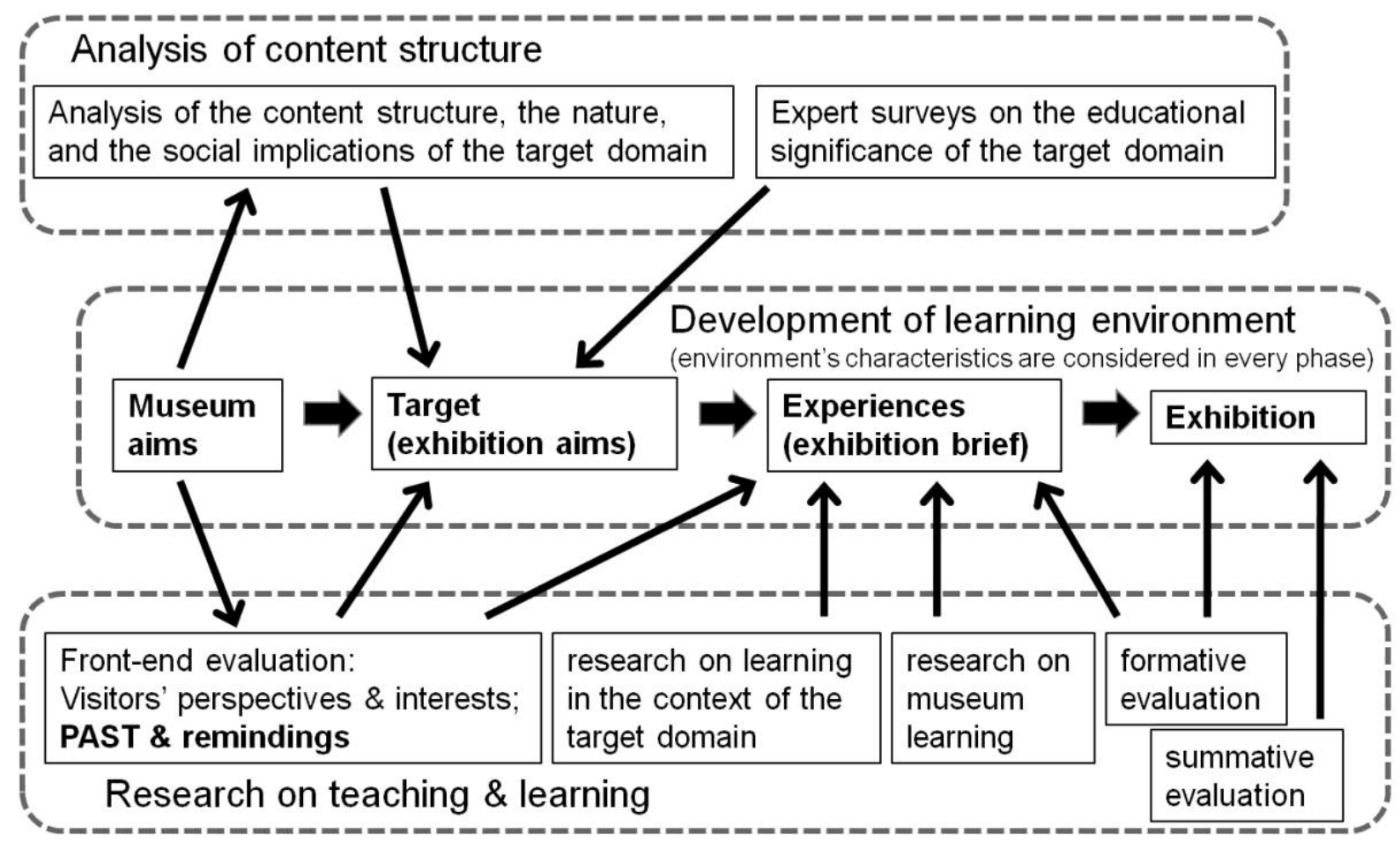

Figure 3. The suggested procedure for informing exhibition development with educational research. 


\section{The process of exhibition development}

The development phase of the exhibition planning process (G. Lord, 2001) can be divided very roughly into four steps: museum aims, exhibition aims, the exhibition brief and the actual exhibition (cf. Grewcock, 2001). This sequence is presented in the middle of Figure 3, corresponding to the component 'Development of learning environment' of MER.

Exhibition development starts by considering the educational aims of the institution in which the exhibition will take place. Besides the general, official goals and the educational role of the science centre or museum (Hooper-Greenhill, 1994; B. Lord, 2001), a number of other aims and practical constraints, e.g. due to sponsors' interests and the resources for the project, must already be taken into account in the first phase of goal setting. After this, the specific educational goals for the exhibition are set (the second step of exhibition development in Fig. 3 ). In terms of the model for PAST, this means the definition of the target, consisting of a set of scientific, technological and/or socio-scientific ideas that are to be represented in the exhibition. On the basis of the target, the third step of the development results in the exhibition brief, i.e. the 'manuscript' for the exhibition (cf. Grewcock, 2001; G. Lord, 2001). Since the exhibition brief contains not only the ideas to be presented but also the means for communicating them, it essentially deals with experiences (again in the terminology of PAST) that the exhibits are aiming to induce in visitors. After the exhibition brief, the planning process continues to the design and implementation phases (G. Lord, 2001), during which the actual exhibition is created.

In these latter phases, some empirical educational research is also of use, namely formative and summative evaluations. These steps are included in Figure 3, even though they are mostly outside the scope of this paper, which focuses on the development phase. This demarcation is justifiable, since by far the greatest potential of educational research is in the initial phase of exhibition planning. As the process continues to design and implementation, its focus typically shifts towards issues that only indirectly concern learning, such as the accessibility, usability, durability, visual attractiveness and mechanical construction of exhibits. The practitioners working on design and implementation focus on the creation of the exhibition according to the brief, and no longer on laying the educational foundations for the exhibition. Apart from the evaluations, the input of educational research should thus already take place in the development phase - in manners outlined in the following.

\section{Content-centred studies in research-based exhibition development}

Analysing the subject matter and the related educational concerns is an important, yet usually neglected part of the exhibition development process. Namely, most museum research aims at understanding the general characteristics of museum learning by directly focusing on the visitors and their interactions in exhibitions, while there has been a lack of research focused on the content of exhibitions (cf. Gilbert \& Stocklmayer, 2001; Mortensen, 2010b). However, in order to improve any kind of science learning through research, not only instructional 
methods but also science content should be considered as problematic (Fensham, 2001). In the approach suggested here, research carried out within the first component of MER, analysis of content structure (the uppermost box in Fig. 3), is used in setting the target of the exhibits - that is, the scientific and socio-scientific content of the exhibition. This is an important and challenging phase in exhibition planning, especially since many science centres want to exhibit emerging fields of science and technology. Such fields are not yet included in school curricula, and there is typically no consensus on the most important ideas and concepts and their relations to each other, let alone their educational aspects. In conventional museum practice, the selection of the exhibition content is guided by the development team's conception of the importance of different issues in the field in question, and professional opinions on the feasibility of these issues for exhibition, considering factors such as the social and psychological characteristics of the resulting exhibits (Gilbert \& Stocklmayer, 2001). Here, it is argued that a research-based approach in choosing the content would complement these ideas in a fruitful way4.

Typically, the general aims and orientation of a museum provide only rough guidelines 5 for choosing the content and defining the educational aims of an exhibition. The development project needs further defined educational goals that are specific to the field to be presented in the exhibition. While contentual, curriculum-like learning goals do not fit an exhibition, the planning team still has to ponder what kind of knowledge of the field in question may, for instance, be relevant in the everyday lives of visitors, and contribute to their ability to make informed decisions on related socio-scientific issues. Such questions are constantly asked in science education research, and reviewing this literature can also aid in selecting the content for informal settings.

Analysis of content structure in MER includes clarification of the subject matter and analysis of its educational significance. Duit (2007) points out that 'content structure' is here understood in a broader sense than usual: educational reconstruction must encompass not only the science concepts and principles, but also the methodological issues as well as the relevance of science in everyday life and society. In a similar way, according to the model for PAST, the target not only consists of the scientific consensus knowledge (cf. Stocklmayer \& Gilbert, 2002), but may also involve knowledge of controversial issues, the nature of science and technology, and their relationships with society and the environment. Indeed, including such aspects in the content structure analysis is crucially important when developing a public exhibition, since an informal learning environment has to relate to the everyday lives of the visitors (see e.g. Falk \& Dierking, 2000). In MER, the research methods of content structure analysis are mostly hermeneutic-analytical: qualitative content and text analyses of leading textbooks on the topic and key publications that characterize the field in question, its historical development and social and philosophical aspects (Duit, 2007; van Dijk \& Kattmann, 2007). Furthermore, Duit (2007, p. 8) points out the possibility to use empirical methods to clarify the educational significance of a large domain - e.g. expert questionnaires or Delphi studies (cf. Komorek \& Duit, 2004).

4 The same need has been pointed out by Schauble and Bartlett (1997).

5 In most cases the official museum goals are expressed in terms of enhancing scientific literacy science museums worldwide have, as pointed out by Henriksen and Frøyland (2000), increasingly commited themselves to this broad and ambiguous task since the beginning of the 1990s. 
Accordingly, defining the target of an exhibition may either draw on analytical literature on the structure, nature and societal aspects of the content, or analyse the content structure and its educational significance by experts surveys, or use both approaches (Fig. 3). In practice, however, it may be impossible to find time to carry out comprehensive literature reviews not to speak of engaging in empirical research - when choosing the exhibition content. Consequently, Science, Technology and Society (STS) studies6 and other analytical reviews that scrutinize the field in question as a whole may be feasible sources. Furthermore, science education research literature includes studies in which a group of scientists and related experts have assembled and systematically compiled a list of central concepts of a field not yet found in textbooks in order to lay the groundwork for education in that field.

The use of all these types of educational literature in content structure analysis is illustrated in the following by discussing the development of an exhibition on nanoscience. In the predominant museum practice, both of the main approaches outlined here are used, but usually in a non-systematic manner. Developers commonly acquaint themselves with some literature on the field in question, and invite some experts on that field to consult in the project. However, educational research is not usually carried out or reviewed at this stage of exhibition development, although it might provide a solid basis for the process. When using science education literature, it must be acknowledged that the analysis of content structure and analysis of educational significance are far more complex processes in informal settings than in formal contexts due to the absence of a curriculum. Therefore, the aims and characteristics of the museum context have to be carefully considered when defining the target (see Fig. 3).

\section{Visitor-centred studies in research-based exhibition development}

The second component of MER, research on teaching and learning (Fig. 1), involves empirical studies on the features of the learning situation in question. According to Duit (2007), these empirical studies include not only research on learners' pre-existing conceptions and affective variables, but also empirical knowledge of teaching and learning processes, instructional methods, learning environments and teachers' perspectives.

In the approach suggested in this paper, empirical educational studies (the lowermost box in Fig. 3) are used to inform many choices in exhibition development. First and foremost, empirical studies should enquire into visitors' typical awareness, interests and associations concerning the topic of the exhibition. While the visitors are not considered as a 'homogenous whole' - each visitor has an individual PAST and remindings - there are usually some patterns in ways of thinking and domains of interest that are worth surveying. Front-end evaluation (or front-end analysis) aims to determine how much the potential visitors already know about the topic of the exhibition, how their prior knowledge can be accommodated within the exhibition, and the level of public enthusiasm for the subject (cf. Grewcock, 2001; Hooper-Greenhill, 1994). It is arguably the most important stage of evaluation in terms of the

6 STS studies usually focus on contemporary fields that are attracting general attention and which therefore also constitute typical topics for science exhibitions. 
success of the exhibition: since it is carried out in the development phase it can - and should have a major influence on the various choices in the exhibition planning process (Grewcock, 2001). Hooper-Greenhill (1994) has argued that in the practice of exhibition development, indepth and efficient assessments of visitors' needs are not common, even though they are highly recommended by scholars of the museum field.

Visitors' perspectives can be studied by reviewing pre-existing survey results or by conducting a survey of one's own - preferably, both approaches should be used. Science education and science communication journals constantly publish survey findings on people's perspectives on emerging fields of science and technology. Although such findings can provide a useful starting point for exhibition development, close attention must be paid to the difference between the sample of the reviewed study and the intended target audience of the museum.

Due to the local and cultural nature of public's perspectives, and the fact that pre-existing surveys seldom provide information that is sufficiently elaborate for exhibition development, it is usually necessary to carry out a specific survey on the potential visitors of the museum in question, investigating their perspectives on the prospective topic of the exhibition. For this there are at least two alternative approaches. One of them is to survey a statistically meaningful sample of the whole target population. Such a study can provide a reliable overview of the potential visitors' interests in, and level of awareness of, the field in question. However, since the sample must be relatively large, the survey typically has to employ a written questionnaire with closed, multiple-choice questions, and some unforeseeable aspects may consequently be missed. Another approach is to conduct a small-sample interview or a focus group study in order to gain a deeper insight into the potential visitors' perspectives. Although statistical significance might be lost, the results may be used together with the findings from earlier surveys and other educational research in order to understand learning difficulties and thinking patterns.

Survey results on the perspectives of the potential visitors should be already available when setting the tentative target of the exhibition (Fig. 3). According to May (2001), a successful audience-responsive approach in museum practice requires that the staff not only rely on their own view when choosing a subject for an exhibition, but carefully study the audience's perspectives and interests. The findings of such 'market analysis' are used together with an understanding of the discipline itself, its current state and problems, when choosing the topic for the exhibition. This phase should also include the identification of the target audience for the exhibition - the definition should, however, be broad enough to accommodate the diverse audience that museums usually have (Allen, 2004). On the basis of further and more contentspecific visitor surveys, the exhibition objectives (the tentative target) should be reconsidered (cf. Grewcock, 2001).

In the further construction of the target (Fig. 3), learners' perspectives are again taken into account, in addition to the content structure analysis. This interplay between analytical and empirical studies is always present in MER, but when developing informal learning environments it is particularly essential. As discussed earlier, the main difference between formal and informal educational contexts is that in the latter the aims and reasons for learning must arise from the learner. Thereby, analysis of content structure for the purpose of 
exhibition development has to take the perspective of the visitors to accommodate the idea of PAST.

The third step in the development of an exhibition, the exhibition brief (i.e. the definition of the intended experiences), can utilise several types of empirical educational research (see Fig. 3 ). The results of the front-end analysis should continue to guide the process by informing the development team of typical PASTs and remindings of the visitors which, in turn, helps in choosing the most effective contexts and means of communication for the exhibits. An exhibition should be designed in a way that it on one hand addresses the most typical interests and ideas of the visitors, and on the other hand uses a variety of approaches and contexts in order to offer something for everybody (cf. Falk \& Storksdieck, 2010; Gilbert \& Stocklmayer, 2001).

Typical learning difficulties and conceptual challenges related to the target should be carefully investigated by reviewing empirical studies on the learning of these concepts and ideas (Fig. 3). Such studies form the vast majority of science education research (Duit, 2007), and review articles related to the specific topic of the exhibition may also be found. Another domain of literature that is helpful when planning experiences consists of research on the general features of exhibitions as learning environments (Fig. 3). The field of research on museum learning is growing rapidly. Again, since comprehensive literature reviews are usually out of the question during exhibition project, it is well advised to focus on publications that discuss exhibitions on topics similar to the one at hand.

Although the exhibition development team may not review museum research other than such content-specific studies, it is certainly important to be aware of the breadth of the literature on general means of communication in museums. Empirical research findings on the general characteristics and typologies of exhibits and their influence on visitors' interaction and learning are of particular use when planning the experiences. Several classification schemes have been suggested in the literature, together with findings on the effectiveness of different exhibit types, e.g. physically interactive exhibits (Boisvert \& Slez, 1995; Tulley \& Lucas, 1991), computer-based exhibits (Heath, vom Lehn, \& Osborne, 2005), open-ended exhibits (Sandifer, 2003), exemplary and analogy-based exhibits (Afonso \& Gilbert, 2007), and immersion exhibits (Mortensen, 2010a; Mortensen, 2010b). Exhibition designers need a comprehensive understanding of the variety of manners of representation and communication, and the ability to search for research articles on some specific exhibit types when needed.

Formative evaluation, carried out in the design phase of the exhibition planning process (G. Lord, 2001), tests the detailed content and the exhibit prototypes with some representatives of the intended audience (cf. Grewcock, 2001). The exhibition brief can be revised on the basis of this pre-testing. The summative evaluation takes place at the end of the implementation phase and addresses the actual exhibition and its visitors. Interviews and questionnaires are chiefly used in the evaluations, but other empirical methods are also possible. Since these evaluations are not carried out in the development phase of the exhibition planning process that this paper focuses on, but in the latter phases, they are not discussed here in detail. 
While informing the planning of the exhibition in question, the studies carried out in connection with exhibition development also contribute to the educational research literature. They can be utilised in forthcoming research and development projects. Such a dual nature, generating new knowledge as well as new practices, is typical for MER and the other variants of design-oriented research (Brown, 1992; Cobb et al., 2003; Duit et al., 1997; Lijnse, 1995; Tiberghien, Vince, \& Gaidioz, 2009). The procedure outlined in this paper may lead not only to the exhibition itself but also to a design framework7 (Edelson, 2002) for the development of such learning environments.

In addition to contributing to the growing body of museum research, properly reported research findings acquired in the process are also relevant in other fields. The results of the front-end analysis can provide valuable information on the public's perspectives on contemporary socio-scientific issues to be used in the fields of science education, science communication, and science and technology studies (STS). The results of formative and summative evaluations, especially if thoroughly discussed in the context of related research, contribute to the general educational literature on fields that form the target of the exhibition. Such outputs may be used to construct content-oriented theories that state the conditions promoting the long-term learning of given topics (Andersson \& Wallin, 2006). Thereby, the approach suggested here interconnects exhibition development with science education research in general, and its design-based research tradition (Tiberghien, Vince, \& Gaidioz, 2009) in particular.

\section{An example: utilising research findings in the development of a nanoscience exhibition}

In order to illustrate the suggested approach, an example is provided here on the use of educational research in the development of a prospective exhibition on nanoscience. The example stems from a research project that aims to map the general challenges and possibilities of nanoscience education, both in formal and informal learning environments. In the course of this research project an exhibition brief is being developed, hopefully to be later implemented in a museum. As part of a research project not primarily leading to an implemented exhibition, the example differs from actual exhibition projects in museums. Although museums cannot typically engage in research activities quite this much, their resources may permit at least some of the research-based approaches presented here.

The process began by considering the general aims of the museum in question (see Fig. 3). On this basis, a few tentative aims of the 'education for citizenship' type were set for the prospective exhibition. They consisted of helping the visitors to (1) feel comfortable and competent with nanoscientific and nanotechnological matters and artefacts; (2) follow media

7 Design frameworks are a type of theory that design research can develop. They 'describe the characteristics that a designed artifact must have to achieve a particular set of goals in a particular context. A design framework is a collection of coherent design guidelines for a particular class of design challenge' (Edelson, 2002). 
discussion on the topics; and (3) form informed opinions on social and ethical issues related to the fields. Such goals are broad enough to accommodate the visitors' personal needs, interests and viewpoints, in line with the idea of the model for PAST. The main purpose of the prospective exhibition is not to prepare visitors for further studies or to educate future nanoscientists and nanoengineers, but to help them to deal with the personal and societal issues concerning nanoscale science and technology.

In order to further define the aims and the target of the exhibition, several types of contentcentred studies have been reviewed, as suggested in Figure 3. Content structure analysis began by reviewing the few hitherto published academic textbooks that aim to cover the whole field of nanoscience. On this basis, a tentative list of scientific key concepts and ideas was formed. The educationally significant issues related to the nature and the societal and ethical aspects of nanoscience were then examined by reviewing the STS studies that scrutinise the field from historical, philosophical and sociological viewpoints. Despite the novelty of the field of nanoscience, a number of STS studies have already been published (e.g. Brune et al., 2006; Baird et al., 2004). These publications have pointed out several issues that render the field educationally significant in terms of scientific literacy (see Laherto, 2010).

In addition to analytical literature, empirical content-centred studies - expert surveys - were also reviewed in order to set the target for the nanoscience exhibition. By far the most influential Delphi study has been carried out in the USA, where a large group of experts compiled a list of "Big Ideas" of nanoscale science and technology that should be incorporated in school curricula (Stevens, Sutherland, \& Krajcik, 2009). The results of a survey on nanoscience-trained science teachers' views of the educational significance of the fields (Laherto, 2011) were additionally taken into account, since educators can be considered as experts in choosing the content for science education - not only in formal but also in informal settings. Put together, the analysis of content structure in defining the target of the exhibition (Fig. 3) revealed not only the central scientific and technological ideas and concepts of nanoscience and nanotechnology (e.g. structure of matter, size-dependent properties, self-assembly and quantum effects), but also a number of educationally interesting features in the nature of these fields (e.g. interdisciplinarity, the 'technoscientific' character, the distinctive roles of modeling, simulations and imaging) and in their interrelationships with society (potential benefits and risks regarding society, the environment and health) that are worth addressing in the exhibition (for a closer look at the results of the content structure analysis, see Laherto, 2010; 2011).

However, as argued in the previous section, an at least equally important approach in defining the target is front-end evaluation (Fig. 3). The example project involved a review of a variety of polls and surveys on public perceptions of nanoscience (for a compilation of the surveys, mostly from North America, see Crone, 2010). These results were complemented by conducting a survey of potential visitors (Laherto, 2008) using the small-sample approach (see the approaches discussed earlier). The results highlighted some fields of nanoscience and nanotechnology that the potential visitors might find especially interesting and relevant to them.

In the third phase of exhibition planning (the exhibition brief, see Fig. 3), the findings of the same visitor survey were utilized in order to identify the typical learning challenges that must 
be taken into account when designing the actual exhibits. The outcomes of the survey pointed out, for instance, that it is difficult to convey the right epistemological ideas with the electron (or atomic force) microscope images widely used in nanoscience communication (Laherto, 2008). The phase of setting the exhibition brief was also informed with a review of the educational research literature on the teaching and learning of nanoscience. As only a quite limited (although rapidly growing) amount of such research has been published, it was not very problematic to demarcate the literature to be analysed - and a comprehensive and recent review article was also available (Hingant \& Albe, 2010). A few common themes clearly emerged from the literature, and the analysis focused on these. Several studies have, for example, shown that people of all ages have major problems in understanding the nanoscale (e.g. Castellini et al., 2007; Tretter, Jones, Andre, Negishi, \& Minogue, 2006), but scale conception can be supported by teaching the continuum of scales, using relative comparisons instead of absolute sizes, providing size landmarks and promoting proportional reasoning (Tretter, 2008). Such educational strategies were also found to be appropriate for exhibitions, and such exhibits were consequently included in the exhibition brief. The review additionally supported the findings of the visitor survey, implying that special attention has to be paid when communicating the nanoscale using electron microscope images in order to avoid epistemological misconceptions. Furthermore, literature on the learning of nanoscale science highlighted the educational potential of real research instruments such as atomic force microscopes (Hingant \& Albe, 2010) - which are usually unobtainable for schools but perhaps not for museums.

Lastly, the research-based groundwork for the exhibition involved a review of research findings on museum learning (Fig. 3), but focusing on reports on previous nanoscience exhibitions. While several exhibitions on this topics have been launched in recent years in museums and science centres all over the world, only a few publications have reported the experiences of these projects from an educational viewpoint. When discussing the Brazilian NanoAventura exhibition, Murriello, Contier and Knobel (2006) stress that the most important museographic and communicational challenge in designing exhibits on NST relates to the fact that the fields are based on objects that are invisible to the naked eye. Exactly the same notion is also stated in an evaluation of It's a Nano World, a travelling exhibition funded by the National Science Foundation in the USA (Batt, Waldron, \& Trautmann, 2004). While NanoAventura solved the dilemma of displaying nano-objects in an exhibition by using computer games and virtual representations, It's a Nanoworld employed concrete macroscopic models and analogies. For the exhibition brief, both types of exhibits were chosen. The literature review increased understanding of the advantages and disadvantages of different museographic approaches, thereby making it possible to use the approaches deliberately.

\section{Conclusions}

While museum learning is commonly seen as 'a vital component of the lifelong learning that we now perceive as essential to the development of both the individual and his or her society' (B. Lord, 2007), Hooper-Greenhill (1994) has argued that museums and science centres have failed in implementing this educational function. While this paper does not claim to provide a solution to this alleged problem, it does suggest how utilising the findings of educational 
research in the development of science exhibitions might improve the educational potential of these learning environments. The suggested approach integrates two models that have both been widely used in educational research but for very different purposes: the Model of Educational Reconstruction (MER) for the development of teaching-learning sequences and science courses, and the Model for the Personal Awareness of Science and Technology (PAST) for describing visitors' interactions with interactive science centre exhibits. Here, it is argued that a combination of these models may be employed in exhibition development. MER provides a specification of the different domains of literature and the types of research that can be utilised in the process, whereas PAST specifies the purposes of these studies in terms of supporting visitors' experiences with the exhibits.

As a personal constructivist model, PAST coheres with the epistemological and learningtheoretical position of MER. There is a difference, however, in the orientation of the models regarding educational objectives. In MER, the learning goals are primarily defined by the curriculum and analysis of the content structure. This is, of course, natural for a model that was originally intended for the development of formal education. However, if this orientation was transferred to informal settings as such, it would contradict the fundamental nature of the concept of personal awareness of science technology. Indeed, the model for PAST specifically opposes any pre-defined learning objectives or other manifestations of the 'deficit model' idea (see Wynne, 1993), or the traditional interpretation of 'public understanding of science'. Fortunately, MER is sufficiently flexible - and constructivist - to allow an orientation that suits the free-choice nature of learning in science centre exhibitions.

The suggestions put forth here might be helpful in developing educationally sound exhibitions, and in bringing museum practice and educational research closer together. However, the actual way in which these suggestions are used in relation to all the other aspects of exhibition development fully relies on museum professionals. Their expertise and intuition is indispensable when selecting which pieces of research to draw on, balancing different concerns, contents and methods, and making the 'best fit' (Grewcock, 2001) in the varying situations of exhibition development. The process has far too many factors to be inclusively modelled. The purpose of this paper is certainly not to downplay or override the expertise of exhibition developers, but to suggest resources for their use. In a typical exhibition development project the museum practitioners cannot, due to the limited time and resources, engage in research to the same extent as in the somewhat idealistic case presented in this paper. It is left up to the professionals to proportion the educational research findings to the other important considerations.

It is impossible to empirically test a model like MER in a strong sense (Duit, Gropengiesser, Kattman, Komorek, \& Parchmann, forthcoming), and the same holds for the adaptation of MER suggested here. Such a model needs a solid theoretical justification (as aspired in this paper), and its usability will be assessed when applied to exhibition projects in museums and science centres. The example presented here of the development of a nanoscience exhibition provides a starting point for the evaluation of the proposal's practical value.

Returning to Barry Lord's (2001, p. 19) three questions with which the process of exhibition development should start, the approach outlined here offers some research-based means to address each of them. In accordance with the idea of PAST, the first question, "What meanings do we wish to communicate?', calls for the above-discussed empirical studies in 
order to identify the interests and other perspectives of visitors. While analysis of content structure, including literature analyses and expert surveys, should also be used in defining the target, the personal awareness and interest of potential visitors must still be the key here. For the same reason, the second question, 'To whom do we intend to communicate these meanings?', must be resolved in the first place. Visitor studies can also inform the selection of the target audience. The last question, 'What are the most appropriate means of communicating these meanings?', deals with the planning of exhibits that are likely to induce experiences fruitful for enhancing visitors' $P A S T$. As argued in this paper, this phase of exhibition development can be informed with literature on learning within the target domain, in addition to the visitor studies and the general literature on museum learning (see Fig. 3).

Both models, MER and PAST, comprise elements from several educational theories employed in museums (Hein, 1998). Together, they provide an approach for developing an exhibition with an epistemological and learning-theoretical orientation that follows the lines of the 'constructivist museum' suggested by Hein (1998, p. 155-179): the scientific content of an exhibition is considered as a human construction, and visitors' perspectives are taken into account and their individual interpretations are supported.

\section{Acknowledgements}

I want to thank Marianne Achiam, Robert Evans and Nana Quistgaard for organizing the excellent 'Didactics of science centres and museums' course at the University of Copenhagen a few years ago. Our discussions during that course inspired this paper. I also am grateful to Reinders Duit, Jari Lavonen, Heimo Saarikko and Suvi Tala for their valuable comments on earlier drafts of the paper.

\section{References}

Afonso, A., \& Gilbert, J. (2006). The use of memories in understanding interactive science and technology exhibits. International Journal of Science Education, 28(13), 15231544.

Afonso, A., \& Gilbert, J. (2007). Educational value of different types of exhibits in an interactive science and technology center. Science Education, 91(6), 967-987.

Aiello-Nicosia, M. L., \& Sperandeo-Mineo, R. M. (2000). Educational reconstruction of physics content to be taught and of pre-service teacher training: A case study. International Journal of Science Education, 22(10), 1085-1097.

Allen, S. (2004). Designs for learning: Studying science museum exhibits that do more than entertain. Science Education, 88(S1), S17-S33.

Anderson, D., Storksdieck, M., \& Spock, M. (2007). Understanding the long-term impacts of museum experiences. In J. Falk, L. Dierking, \& S. Foutz (Eds.), In Principle, In Practice: Museums as Learning Institutions (pp. 197-215). Lanham, MD: AltaMira. 
Andersson, B., \& Wallin, A. (2006). On developing content-oriented theories taking biological evolution as an example. International Journal of Science Education, 28(6), 673-695.

Baird, D., Nordmann, A., \& Schummer, J. (Eds.). (2004). Discovering the nanoscale. Amsterdam: IOS Press.

Batt, C., Waldron, A., \& Trautmann, C. (2004). It's a Nano World: A study of use. Retrieved September 28, 2011, from http://eduinc.org/ItsaNanoWorldSummativeStudy.pdf.

Boisvert, D., \& Slez, B. (1995). The relationship between exhibit characteristics and learningassociated behaviors in a science museum discovery space. Science Education, 79(5), 503-518.

Brown, A. (1992). Design experiments: Theoretical and methodological challenges in creating complex interventions in classroom settings. The Journal of the Learning Sciences, 2(2), 141.

Brune, H., Ernst, H., Grunwald, A., Grünwald, W., Hofmann, H., Krug, H., Janich, P., Mayor, M., Rathgeber, W., Schmid, G., Simon, U., Vogel, V., \& Wyrwa, D. (2006). Nanotechnology: Assessment and perspectives. Berlin Heidelberg: Springer.

Bybee, R. (2001). Achieving scientific literacy: Strategies for insuring that free choice science education complements national formal science education efforts. In J. Falk (Ed.), Free-choice education: How we learn science outside of school (pp. 44-63). New York: Teachers College Press.

Castellini, O., Welejko, G., Holladay, C., Theim, T., Zenner, G., \& Crone, W. (2007). Nanotechnology and the public: Effectively communicating nanoscale science and engineering concepts. Journal of Nanoparticle Research, 9(2), 183-189.

Cobb, P., Confrey, J., diSessa, A., Lehrer, R., \& Schauble, L. (2003). Design experiments in educational research. Educational Researcher, 32(1), 9-13.

Crone, W. (2010). Bringing nano to the public: A collaboration opportunity for researchers and museums. Journal of Nano Education, 2, 102-116.

Davidsson, E., \& Sørensen, H. (2010). Sponsorship and exhibitions at Nordic science centres and museums. Museum Management and Curatorship 25(4), 345-360.

Dierking, L., Falk, J., Rennie, L., Anderson, D., \& Ellenbogen, K. (2003). Policy statement of the 'informal science education' ad hoc committee. Journal of Research in Science Teaching, 40(2), 108-111.

Duit, R. (2007). Science education research internationally: Conceptions, research methods, domains of research. Eurasia Journal of Mathematics, Science \& Technology Education, 3(1), 3-15.

Duit, R., Gropengiesser, H., \& Kattman, U. (2005). Towards science education research that is relevant for improving practice: The model of educational reconstruction. In $\mathrm{H}$. Fischer (Ed.), Developing standards in research on science education (pp. 1-9). London: Taylor \& Francis.

Duit, R., Gropengiesser, H., Kattman, U., Komorek, M., \& Parchmann, I. (forthcoming). The model of educational reconstruction - A framework for improving teaching and learning science. In J. Dillon, \& D. Jorde (Eds.), The World of Science Education Handbook of Research in Europe. Rotterdam: Sense Publishers.

Duit, R., Komorek, M., \& Wilbers, J. (1997). Studies on educational reconstruction of chaos theory. Research in Science Education, 27(3), 339-357.

Edelson, D. (2002). Design research: What we learn when we engage in design. Journal of the Learning Sciences, 11(1), 105.

Falk, J., \& Dierking, L. (2000). Learning from museums: Visitor experiences and the making of meaning. Walnut Creek, CA: AltaMira Press. 
Falk, J., Dierking, L., \& Foutz, S. (2007). Preface. In J. Falk, L. Dierking, \& S. Foutz (Eds.), In Principle, In Practice: Museums as Learning Institutions (pp. xiii-xx). Lanham, MD: AltaMira.

Falk, J., \& Storksdieck, M. (2010). Science learning in a leisure setting. Journal of Research in Science Teaching, 47(2), 194-212.

Falk, J., Storksdieck, M., \& Dierking, L. (2007). Investigating public science interest and understanding: evidence for the importance of free-choice learning. Public Understanding of Science, 16(4), 455-469.

Fensham, P. (2001). Science content as problematic - issues for research. In H. Behrendt, H. Dahncke, R. Duit, W. Gräber, M. Komorek, A. Kross, \& P. Reiska (Eds.), Research in Science Education - Past, Present, and Future (pp. 27-41). Dordrecht: Kluwer Academic Publishers.

Gilbert, J., \& Stocklmayer, S. (2001). The design of interactive exhibits to promote the making of meaning. Museum Management and Curatorship, 19(1), 41-50.

Gouvêa de Sousa, G., Valente, M. E., Cazelli, S., Alves, F., Marandino, M., \& Falcão, D. (2002). A study of the process of museographic transposition in two exhibitions at the MAST. In C. Dufresne-Tasse (Ed.), Evaluation: Multipurpose applied research (pp. 108-124). Québec: Éditions MultiMondes.

Grewcock, D. (2001). Before, during and after: Front-end, formative and summative evaluation. In B. Lord, \& G. Lord (Eds.), The manual of museum exhibitions (pp. 4457). Walnut Creek, CA: AltaMira.

Heath, C., vom Lehn, D., \& Osborne, J. (2005). Interaction and interactives: collaboration and participation with computer-based exhibits. Public Understanding of Science, 14(1), 91-101.

Hein, G. (1998). Learning in the museum. London: Routledge.

Henriksen, E., \& Frøyland, M. (2000). The contribution of museums to scientific literacy: views from audience and museum professionals. Public Understanding of Science, 9(4), 393-415.

Hingant, B., \& Albe, V. (2010). Nanosciences and nanotechnologies learning and teaching in secondary education: a review of literature. Studies in Science Education, 46(2), 121152.

Hooper-Greenhill, E. (1992). Museums and the shaping of knowledge. London: Routledge.

Hooper-Greenhill, E. (1994). Museum education. In E. Hooper-Greenhill (Ed.), The educational role of the museum (1st ed., pp. 229-257). London: Routledge.

Komorek, M., \& Duit, R. (2004). The teaching experiment as a powerful method to develop and evaluate teaching and learning sequences in the domain of non-linear systems. special issue. International Journal of Science Education, 26(5), 619-633.

Laherto, A. (2008). Public understanding of nanoscience - current state and relevance to scientific literacy. Paper presented in GIREP 2008 Conference, Nicosia, Cyprus, 18.22.8.2008.

Laherto, A. (2010). An analysis of the educational significance of nanoscience and nanotechnology in scientific and technological literacy. Science Education International, 21(3), 160-175.

Laherto, A. (2011). Incorporating nanoscale science and technology into secondary school curriculum: Views of nano-trained science teachers. NorDiNa - Nordic Studies in Science Education, 7(2), 126-139.

Lijnse, P. L. (1995). 'Developmental research' as a way to an empirically based 'didactical structure' of science. Science Education, 79(2), 189-199. 
Lord, B. (2001). The purpose of museum exhibitions. In B. Lord, \& G. Lord (Eds.), The manual of museum exhibitions (pp. 11-26). Walnut Creek, CA: AltaMira.

Lord, B. (2007). Introduction. In B. Lord (Ed.), The manual of museum learning (pp. 3-4). Lanham, MD: AltaMira.

Lord, G. (2001). Introduction: The exhibition planning process. In B. Lord, \& G. Lord (Eds.), The manual of museum exhibitions (pp. 1-8). Walnut Creek, CA: AltaMira.

May, M. (2001). Exhibition ideas: Integrating the voices of communities and audiences. In B. Lord, \& G. Lord (Eds.), The manual of museum exhibitions (pp. 32-38). Walnut Creek, CA: AltaMira.

Mehta, J. (1997). STL in informal and non-formal settings. In E. Jenkins (Ed.), Innovations in science and technology education vol. VI (pp. 95-108). Paris: UNESCO.

Miles, R., \& Tout, A. (1991). Impact of research on the approach to the visiting public at the natural history museum, London. International Journal of Science Education, 13(5), 543-549.

Mortensen, M. F. (2010a). Designing immersion exhibits as border-crossing environments. Museum Management and Curatorship, 25(3), 323-336.

Mortensen, M. F. (2010b). Museographic transposition: The development of a museum exhibit on animal adaptations to darkness. Éducation \& Didactique, 4(1), 119-137.

Murriello, S., Contier, D., \& Knobel, M. (2006). Challenges of an exhibit on nanoscience and nanotechnology. Journal of Science Communication, 5(4).

Neumann, K., Schumacher, D., \& Welzel, M. (2005). Educational reconstruction of a physics laboratory course for physics students. Paper presented at the Conference of the European Science Education Research Association (ESERA) 2005, August 28th September 1st, Barcelona, Spain.

Rennie, L., \& Johnston, D. (2004). The nature of learning and its implications for research on learning from museums. Science Education, 88(Suppl. 1), S4-S16.

Sandifer, C. (2003). Technological novelty and open-endedness: two characteristics of interactive exhibits that contribute to the holding of visitor attention in a science museum. Journal of Research in Science Teaching, 40(2), 121-137.

Schauble, L., \& Bartlett, K. (1997). Constructing a science gallery for children and families: The role of research in an innovative design process. Science Education, 81, 781-793.

Simonneaux, L., \& Jacobi, D. (1997). Language constraints in producing prefiguration posters for a scientific exhibition. Public Understanding of Science, 6(4), 383-408.

Stevens, S., Sutherland, L., \& Krajcik, J. (2009). The Big Ideas of Nanoscale Science and Engineering. Arlington, VA: NSTA Press.

Stocklmayer, S., \& Gilbert, J. (2002). New experiences and old knowledge: Towards a model for the personal awareness of science and technology. International Journal of Science Education, 24(8), 835-58.

Tiberghien, A., Vince, J., \& Gaidioz, P. (2009). Design-based Research: Case of a teaching sequence on mechanics. International Journal of Science Education, 31(17), 22752314.

Tretter, T. (2008). Nanoscience and conceptions of size and scale in precollege education. In A. E. Sweeney, \& S. Seal (Eds.), Nanoscale science and engineering education (pp. 149-166). CA: American Scientific Publishers.

Tretter, T., Jones, M., Andre, T., Negishi, A., \& Minogue, J. (2006). Conceptual boundaries and distances: Students' and experts' concepts of the scale of scientific phenomena. Journal of Research in Science Teaching, 43(3), 282-319. 
Tulley, A., \& Lucas, A. (1991). Interacting with a science museum exhibit: Vicarious and direct experience and subsequent understanding. International Journal of Science Education, 13(5), 533-542.

van Dijk, E. M., \& Kattmann, U. (2007). A research model for the study of science teachers' PCK and improving teacher education. Teaching and Teacher Education: An International Journal of Research and Studies, 23(6), 885-897.

Wynne, B. (1993). Public uptake of science: A case for institutional reflexivity. Public Understanding of Science, 2(4), 321-337. 